\title{
Seasonal progression of factors limiting phytoplankton pigment biomass in the Rhode River estuary, Maryland (USA). I. Controls on phytoplankton growth
}

\author{
C. L. Gallegos *, T. E. Jordan
}

Smithsonian Environmental Research Center, PO Box 28, Edgewater, Maryland 21037, USA

\begin{abstract}
Experiments to measure phytoplankton growth rates and microzooplankton grazing rates, both with and without additions of nutrients, were conducted over a 5 yr span to determine the relative roles of physical factors, nutrients, and microzooplankton grazing in regulating phytoplankton pigment biomass in the Rhode River estuary (Maryland, USA). Microzooplankton grazing rate was overall only weakly correlated with phytoplankton growth rate, although fluctuations in the rates appeared to parallel one another for restricted periods. Grazing was about $73 \%$ of growth rate at ambient nutrients during 1995, a year in which the two were correlated. In winter and early spring, phytoplankton growth rates were low and unaffected by nutrient additions. In late spring, stimulation of growth by nutrient addition was more common, but microzooplankton grazing was partially effective in relieving nutrient limitation. Growth enhancement by nutrient addition was most common in summer, and microzooplankton grazing was less effective at relicving nutrient limitation. $\mathrm{P}$ or $\mathrm{N}$ addition stimulated phytoplankton growth in late spring and autumn, but only $\mathrm{N}$ addition stimulated growth in summer. Temperature constrained upper bounds of observed growth rates throughout the year, but many observed growth rates were far below the temperature-dependent maximum, even with nutrients added. Considered as a single group, temperature-normalized growth rates were poorly related to in situ daily photon flux; but the rates appeared to fall into species-dependent higher and lower groups. The higher growth rates were statistically associated with the diatoms Thalassiosira pseudonana, Thalassiosira sp., and Nitzschia longissima. The lower growth rates were associated with the dinoflagellates Gyrodinium uncatenum and Prorocentrum minimum. Results suggest that interpretation of bioassay experiments requires consideration of both grazing effects and species composition of the phytoplankton community. Nutrient stimulation of some slow growing assemblages may be difficult to detect in $1 \mathrm{~d}$ incubation experiments
\end{abstract}

KEY WORDS: Phytoplankton Estuary Growth - Nutrients Grazing - Light Temperature

\section{INTRODUCTION}

One of the goals of estuarine phytoplankton research is to understand the connections between phytoplankton abundance in estuaries and processes taking place in hydrologically linked terrestrial landscapes and adjacent coastal waters. A first step in developing such an understanding is the identification of factors limiting phytoplankton production in estuaries, and their

•E-mail:gallegos@serc.si.edu seasonal progression. Phytoplankton abundance in estuaries is known to depend on factors such as light (Cloern 1987), nutrients (D'Elia et al, 1986) and zooplankton grazing (Verity 1986). In portions of some systems a single factor such as turbidity (Cloern 1987) or nitragen (Rudek et al. 1991, Mallin et al. 1993) may regulate phytoplankton production year round. In other systems the limiting factor undergoes seasonal shifts with changes in, e.g., river flow (Fisher et al. 1992) or physical factors (temperature and incident irradiance; Pennock \& Sharp 1994). 
One well-known seasonal shift in limiting factors is the transition from limitation by physical factors in winter to nutrient limitation in late spring and summer In Chesapeake Bay, this transition is accompanied by changes in the structure and function of the phytoplankton community from dominance by diatoms that sequester available nutrients and sink out of the surface layer in spring, to a highly productive community of autotrophic flagellates growing on recycled nutrients in the summer (Malone et al. 1988, 1996). In nutrient recycling systems, grazing (mostly by microzooplankton; Harrison 1992) regenerates the nutrients that regulate phytoplankton growth. That is, nutrient supply depends on the intensity of grazing, so that tight coupling (i.e. high correlation) between phytoplankton growth and microzooplankton grazing is sometimes observed (Verity 1986). Observations of correlated rates of phytoplankton growth and microzooplankton grazing are often based on studies of limited duration (e.g. individual cruises; Burkhill et al. 1987) or a few widely spaced experiments (Gallegos 1989), so that the seasonal development and interannual variability of the correlation between phytoplankton growth and microzooplankton grazing needs further investigation.

Several recent studies on nutrient regulation of phytoplankton net production in estuaries have demonstrated seasonal shifts from phosphorus limitation in the winter and spring to nitrogen limitation in summer (D'Elia et al. 1986, Fisher et al. 1992, Malone et al. 1996), or the reverse (Paasche \& Erga 1988). Evidence for such seasonal shifts has come from examination of changing molar ratios of $N: P$, from short term enrichment studies, from physiological indicators such as the turnover time of $P$, and from in situ mesocosm studies involving $\mathrm{N}$ and $\mathrm{P}$ factorial additions to the whole plankton community (D'Elia et al. 1986). In the Rhode River, Maryland (USA), a shallow subestuary of Chesapeake Bay, Jordan et al. (1991a) demonstrated a seasonal shift of the N:P ratio of dissolved nutrients that would indicate potential $P$ limitation in spring Other evidence, however, suggested $N$ limitation in spring. For example, phytoplankton chlorophyll in the spring, lagged by 3 wk (Jordan et al. 1991b), correlated best with flow of the Susquehanna River, the principal source of freshwater and excess $\mathrm{N}$ to the upper Chesapeake Bay (Fisher et al. 1992). N limitation is also suggested by observations that phytoplankton chlorophyll in the summer correlated best with $\mathrm{N}$ inputs the previous spring (Jordan et al. 1991b). Thus, in the Rhode River, elemental ratios and correlational studies of biomass and allochthonous nutrient inputs do not give a consistent picture of the seasonal progression of nutrient limitation. Additional evidence is needed to clarify the seasonal progression of limiting factors in the Rhode River
The objective of this work is to determine the relative roles of N, P, grazing and physical factors, in regulation phytoplankton growth in the Rhode River In particular, we wish to determine the temporal sequence of limitation by different factors, as well as interactions amongst them. We employ short-term dilution and nutrient-enrichment experiments to measure phytoplankton growth and microzooplankton grazing rates, and to distinguish grazing and nutrient limitation of phytoplankton pigment accumulation. In the companion paper (Gallegos \& Jordan 1997 in this issue) we develop a model of nutrient-limited phytoplankton growth, based on that of Riegmann \& Mur (1984), to examine how the sequence of limitation depends on interactions between environmental forcing and phytoplankton physiology.

\section{METHODS}

Study site. The Rhode River $\left(38^{\circ} 53^{\prime} \mathrm{N}, 76^{\circ} 32^{\prime} \mathrm{W}\right)$ is one of several tributary embayments or subestuaries on the western shore of the mesohaline region of Chesapeake Bay in Maryland, USA. It is 550 ha in area. Depth at mean low water varies from $4 \mathrm{~m}$ at the mouth to $<1 \mathrm{~m}$ in the upper subtidal regions. Land composition in the 2300 ha watershed of Muddy Creek, the principal freshwater source to the upper subestuary, is mostly forest and farms (Jordan et al. 1991a). For purposes of sampling and modeling we have divided the subestuary into segments numbered sequentially from 1 seaward of the mouth to 7 and 8 representing the 2 most landward of the tidal branches (Jordan et al. 1991a). This analysis focuses on a segment of the Rhode River that is influenced both by Muddy Creek and by the Susquehanna River (segment 4; Jordan et al. 1991a, Gallegos et al. 1992).

The Rhode River is eutrophic. Long-term average chlorophyll concentrations during summer in segment 4 were about $50 \mathrm{mg} \mathrm{m}^{-3}$ from 1978 to 1989 (see Jordan et al. 1991a), but in recent years the summertime average has been 25 to $30 \mathrm{mg} \mathrm{m}^{-3}$. Seasonally averaged nutrient concentrations in segment 4 ranged from $<0.1$ to $1.4 \mu \mathrm{M}$ for dissolved inorganic phosphate (DIP), and from $<0.2$ to $36 \mu \mathrm{M}$ for nitrate (Jordan et al. 1991a). Molar concentrations of dissolved Si only rarely have fallen below those of DIN, and when they have, DIP was always $<[\mathrm{Si}] / 16$ (Correll unpubl.), the approximate Redfield proportion for diatoms. Thus we expect Si always to be present in excess.

Dilution experiments. Phytoplankton growth rates and microzooplankton grazing rates were determined by the dilution technique (Landry \& Hassett 1982) utilizing highly diluted incubations as suggested for eutrophic systems by Gallegos (1989). Two types of 
dilution experiments were performed. The first, conducted at monthly intervals during the ice-free season, was designed to estimate phytoplankton growth rate and microzooplankton grazing rate with good resolution of the complete response of apparent growth rate to the fraction of seawater (Gallegos 1989). Duplicate incubations were carried out at 6 fractions of whole estuary water at dilution levels $D=1.0,0.8,0.4,0.2$, 0.1 , and 0.05, all enriched with added $\mathrm{N}\left(\mathrm{NaNO}_{3}\right)$ and $\mathrm{P}\left(\mathrm{Na}_{2} \mathrm{HPO}_{4}\right)$ in a molar ratio of 10:1 N:P. Additional incubations without added nutrients were conducted at $D=0.4$ and either $D=1.0$ or $D=0.05$. Level of nitrate addition (rounded to the nearest $10 \mu \mathrm{M}$ ) was determined as $\mu \mathrm{M} \mathrm{N}$ added $\approx 2 \times\left(\mathrm{mg} \mathrm{m}^{-3}\right.$ chlorophyll a) where the chlorophyll a was determined the previous week or, when it appeared to have changed, the same day on a brief $(-3 \mathrm{~h})$ extraction while the diluent was being prepared.

The second type of dilution experiment, conducted at monthly intervals from 1993 to 1996, two weeks after the first type, was designed to identify whether $\mathrm{N}$ or $\mathrm{P}$ was more limiting to phytoplankton net growth rate. The experiments were similar in design to those of Andersen et al. (1991) and Elser \& Frees (1995). Duplicate incubations with either added N, P, or neither (i.e. ambient nutrients) were conducted at dilution levels $D=$ $1.0,0.4$, and 0.05 . In this second type of dilution experiment, fewer dilution levels were run due to the added incubations from the separate additions of $\mathrm{N}$ and $\mathrm{P}$.

The addition of nutrients at different dilution levels in each type of dilution experiment allows us to examine the interaction between limitation by nutrients and by microzooplankton grazing. At the lowest dilution factor, $D=0.05$, grazing is virtually eliminated, and the initial phytoplankton biomass is highly diluted, thereby placing minimal demand on the dissolved stock of available nutrients. Enhancement of net growth rate by nutrient addition at $D=0.05$ indicates that nutrients are in short enough supply to limit phytoplankton intrinsic growth rate. At $D=1.0$, initial undiluted phytoplankton biomass is maximal and places the highest demand on the ambient nutrients; but grazing by microzooplankton may limit accumulation of biomass and regenerate nutrients (Andersen et al. 1991) over the course of a $1 \mathrm{~d}$ incubation, preventing complete manifestation of nutrient limitation. Stimulation of growth by nutrient addition at $D=1.0$ indicates the degree to which nutrients limit the yield of new phytoplankton biomass at the prevailing conditions of nutrient concentrations and grazing rates. The incubation at $D=0.4$ measures a potential for nutrient limitation, because the partially diluted initial phytoplankton standing stock places moderate demand on the ambient nutrient stocks, but the dilution partially releases the phytoplankton from grazing pressure (when present), thereby permitting utilization of added nutrients to a greater extent than at the unmodified grazing rate.

Surface water for diluent was sampled from a pier about 09:00 $\mathrm{h}$ local time, returned to the laboratory, and filtered through $47 \mathrm{~mm} \mathrm{GF/F} \mathrm{filters.} \mathrm{Because} \mathrm{of} \mathrm{the}$ high concentrations of seston in the Rhode River, several hours were required to filter the $\sim 251$ needed as diluent. After preparation of the diluent, another surface sample for live plankton. was collected by bucket. The separate collections for diluent and live plankton were done to minimize containment time of the plankton prior to commencing the incubations. To avoid damage to protozoa, the samples were not screened for copepods. The dilutions were incubated in 21 polycarbonate bottles suspended in situ at a depth of $1 \mathrm{~m}$ (average depth in segment 4 is $2 \mathrm{~m}$ ) for $24 \mathrm{~h}$, beginning at about 14:00 h local time. Nutrient addition bioassays are generally incubated longer than $1 \mathrm{~d}$ as we have chosen, because longer times are sometimes needed for the community to respond (Howarth 1988). We chose $1 \mathrm{~d}$ incubations because of our interest in factors limiting the phytoplankton community present at the initiation of the experiment, rather than an experimentally altered community.

Apparent growth rates in individual incubations were determined as $\ln \left[B_{24}(D) / B_{0}(D)\right]$, where $B_{0}$ and $B_{24}$ are, respectively, the initial and final chlorophyll concentrations at dilution level $D$. In most experiments, growth $(\mu)$ and grazing $(g)$ rates were estimated by linear regression of apparent growth rate against fraction of unfiltered estuary water (Landry \& Hassett 1982). Apparent growth rates in the enriched incubations were used in the regressions to calculate microzooplankton grazing rates in the first type of dilution experiment. In the second type of dilution experiment we selected the treatment having the consistently highest apparent growth rates for use in the regressions to calculate grazing rates. Nonlinearity of feeding kinetics (Gallegos 1989) was infrequent, perhaps due to lower chlorophyll concentrations in recent years (Gallegos unpubl.). When nonlinearity was present, growth rate was estimated by linear regression of apparent growth rate against $D$ at the 2 to 4 lowest dilution factors. In the event of nonlinearity, $g$ was estimated by Eq. (11) of Gallegos (1989). Grazing rates have not been corrected for the growth of microzooplankton during the incubations, and therefore represent a cumulative grazing impact, being greater than the true initial grazing coefficient by a factor of approximately $e^{\mu_{z} / 2}$, where $\mu_{z}=$ net growth rate of microzooplankton in the undiluted incubation (Gallegos et al. 1996). In reporting phytoplankton growth rates at different dilution levels and with or without nutrients, we denote rates without nutrient addition 

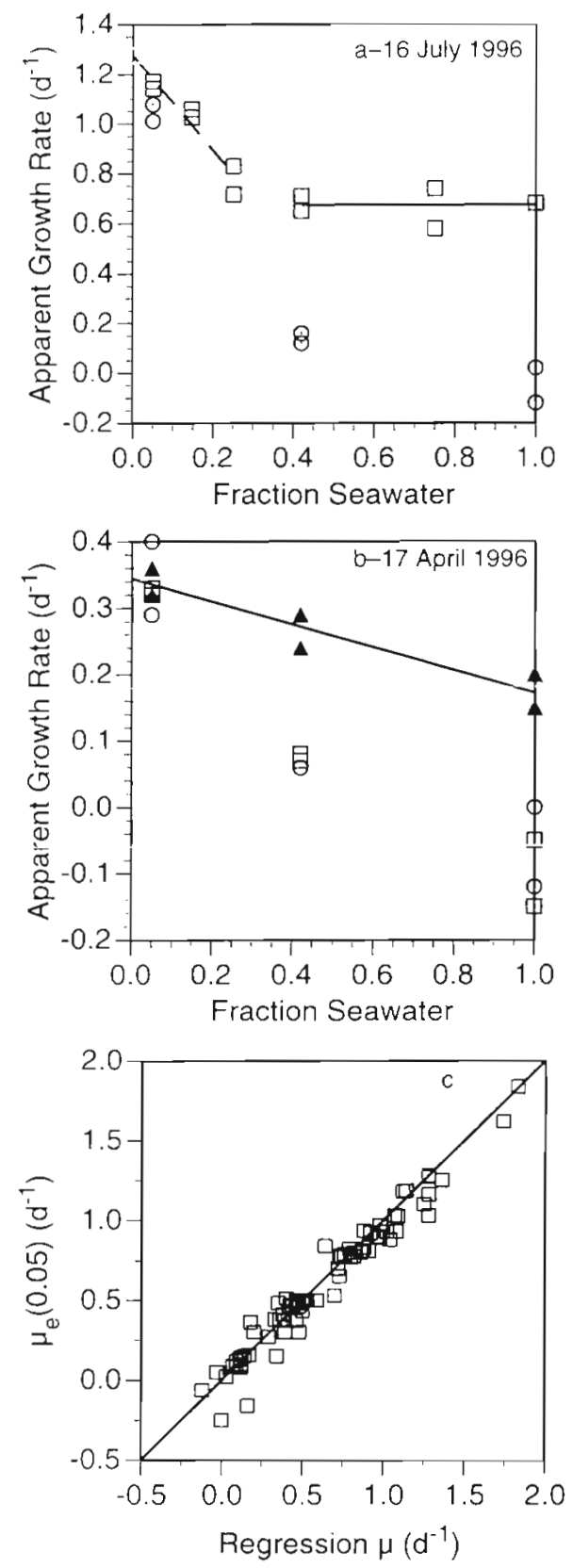

Fig. 1. (a) Example of results of a standard dilution grazing experiment on $16 \mathrm{July}$ 1996, in which microzooplankton feeding kinetics were nonlinear: $(\square)$ incubations with added nutrients (both $\mathrm{N}$ and $\mathrm{P}) ;(\Theta)$ incubations at ambient nutrients. Intercept of dashed line = calculated growth rate; solid line = mean of apparent growth rate in saturated region of curve, used to calculate grazing rate (see text). (b) Example of dilution experiment to identify most limiting nutrient on 17 April 1996. Samples were incubated at 3 dilution factors with: $(\odot)$ no added nutrients; $(\square)$ added $N_{i}$ and $(\Delta)$ added $P$. Phytoplankton growth and microzooplankton grazing rates (respectively) were calculated from intercept and slope of line fitted to added P-incubations. (c) Nutrient enhanced growth rates calculated from chlorophyll change in highly diluted incubations $(D=0.05), \mu_{\mathrm{e}}(0.05)$, compared with rates calculated by regressions. Data from all dates with the subscript a (ambient), and those with nutrients added with the subscript e (enriched). Dilution level is indicated parenthetically, so that, e.g., $\mu_{d}(0.05)$ denotes the net growth rate without nutrient addition at $D=$ 0.05 . We calculated the enhancement due to nutrient enrichment at the different dilution levels, $\Delta \mu(D)$, as $\Delta \mu(D)=\mu_{e}(D)-\mu_{a}(D)$. Variability of the measured rates on seasonal and interannual time scales was assessed by ANOVA. Seasons were designated winter-early spring: January 1-April 10; late spring: April 11-June 21; summer: June 22-September 22; autumn-winter: September 23-December 31.

Laboratory analyses. Samples for chlorophyll analyses were filtered onto Whatman GF/F glass fiber filters and extracted in $90 \%$ acetone at $4^{\circ} \mathrm{C}$ in the dark for about $18 \mathrm{~h}$. Chlorophyll concentrations were calculated from fluorescences read on a Turner Designs 10-AU fluorometer before and after acidification (Holm-Hansen et al. 1965).

Samples for species identification were preserved immediately using $1 \%$ acid Lugol's iodine. For counting, 1 to $10 \mathrm{ml}$ were settled (minimum $4 \mathrm{~h}$ ) and viewed at a magnification of $512 \times$ under an inverted microscope. Abundant taxa were estimated from the number of fields required to count 200 individuals; density estimates of less abundant taxa were based on the number of individuals in 20 fields. All cells were identified to the lowest taxonomic grouping possible, which was nearly always genus or lower. Taxa comprising $<10^{2}$ cells $\mathrm{ml}^{-1}$ were recorded as 'present' and were not entered into the statistical analysis. Because of this lower threshold for counting, density estimates were transformed as $\ln \left(50+\right.$ cells $\left.\mathrm{ml}^{-1}\right)$ for statistical analysis, to avoid extreme bi-modality in the log-transformed counts.

Physical data. Daily averaged in situ water temperature was calculated from hourly averages recorded at $1 \mathrm{~m}$ depth at a recording station about $0.3 \mathrm{~km}$ from the incubation site. Daily incident photon flux density (PFD, 400 to $700 \mathrm{~nm}$ ) was calculated by trapezoidal rule integration of hourly averages of instantaneous PFD measured by a cosine corrected Licor 190SA quantum sensor. Incident PFD was multiplied by $e^{-K_{D}}$, where $K_{D}=$ diffuse attenuation interpolated from measurements made 2 to $7 \mathrm{~d}$ before and after the incubation, to calculate daily PFD at $1 \mathrm{~m}$.

\section{RESULTS}

\section{Example data and analyses}

Both linear and nonlinear responses of apparent growth rate to dilution factor were observed (Fig. 1a, b). We illustrate the variety of responses and the ana- 


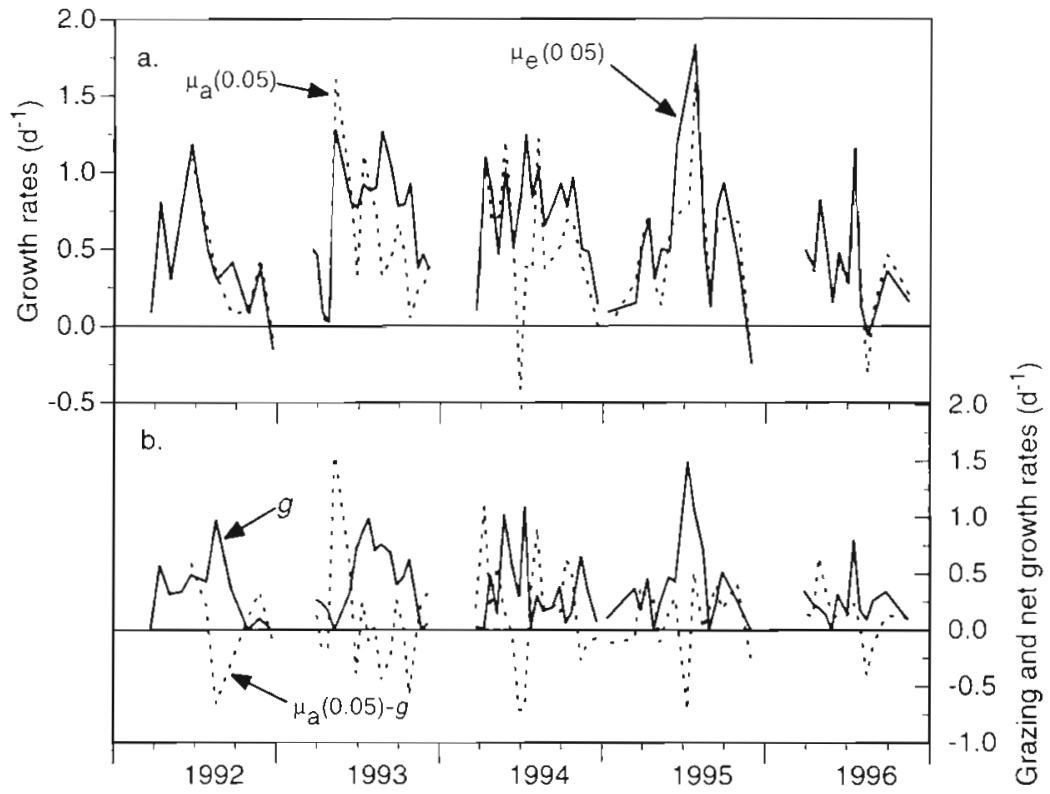

Fig. 2. (a) Time series of nutrient-enhanced phytoplankton growth rate (-), $\mu_{\mathrm{e}}(0.05)$, and growth rate at ambient nutrients (- - ), $\mu_{\mathrm{a}}(0.05)$, measured by dilution experiments in the Rhode River, Maryland (USA), 1992 to 1996 (b) Time series of microzooplankton grazing rate (-), g, and phytoplankton net growth rate at ambient nutrients $(--), \mu_{\mathrm{a}}(0.05)-g, 1992$ to 1996

$\mathrm{D}=0.05,0.21 \mathrm{~d}^{-1}$ at $D=0.4$, and $0.24 \mathrm{~d}^{-1}$ at $D=1.0$.

Nutrient-enhanced growth rates determined at a single dilution factor, $D=$ 0.05 , were nearly identical to those determined by mathematical solution of the equation governing apparent growth rate versus dilution factor, whether linear or nonlinear (Fig. 1c). That is, $D=0.05$ is sufficiently close to zero that grazing is virtually completely eliminated, within the precision of the method. Therefore, the mean of replicate incubations at $D=0.05$ with and without added nutrients can be used in place of the intercepts of complete dilution experiments to assess the effects of nutrient addition on phytoplankton growth rates.

\section{Growth and grazing rates}

Nutrient enhanced growth rates, $\mu_{\mathrm{e}}(0.05)$, varied seasonally from $<0.1 \mathrm{~d}^{-1}$ in early spring to a maximum of about

lytical procedures used with each type of experiment by a few examples. For example, on 16 July 1996 a standard dilution experiment revealed evidence of nonlinear microzooplankton feeding kinetics in nutrient-enhanced apparent growth rates (Fig. 1a, squares). Apparent growth rates at dilution factors $\leq 0.2$ were used to estimate phytoplankton growth rate by linear regression of $\mu=1.28 \mathrm{~d}^{-1}$ (Fig. 1a, dashed line). The average apparent growth rate in the range of saturated microzooplankton grazing was $0.67 \mathrm{~d}^{-1}$ (Fig. 1a, solid line). With these 2 rates, and assuming microzooplankton net growth rate, $\mu_{z}=0 \mathrm{~d}^{-1}$, we can solve Eq. (11) of Gallegos (1989) as follows

$$
\frac{B(1)}{B(0)}=\mathrm{e}^{\mu}-g \frac{\mathrm{e}^{\mu_{\alpha}}-\mathrm{e}^{\mu}}{\mu_{z}-\mu} \quad \text { or } \quad \mathrm{e}^{0.67}=\mathrm{e}^{1.28}-g \frac{1-\mathrm{e}^{1.28}}{-1.28}
$$

thus $g=0.81 \mathrm{~d}^{-1}$. Nutrient addition on this day enhanced apparent growth rates over those at ambient nutrients (Fig. $1 \mathrm{a}$, circles) by 0.53 and $0.72 \mathrm{~d}^{-1}$ at $D=$ 0.4 and $D=1.0$, respectively, but only slightly $\left(0.11 \mathrm{~d}^{-1}\right)$ at $D=0.05$.

On 17 April 1996 an experiment to identify the limiting nutrient revealed stimulation of apparent growth rate by addition of $P$ (Fig. $1 b$, triangles), but not $N$ (Fig. 1b, squares). Microzooplankton feeding kinetics were linear, and thus by linear regression we estimated $\mu=0.36 \mathrm{~d}^{-1}$ and $g=0.23 \mathrm{~d}^{-1}$. Enhancement of apparent growth rate by nutrient (i.e. P) addition was $-0.005 \mathrm{~d}^{-1}$ (i.e. within replicability limits, see below) at
$1.2 \mathrm{~d}^{-1}$ in early to mid-summer (Fig. 2a), with one extreme value of $1.8 \mathrm{~d}^{-1}$ in summer 1995. Variance of nutrient-saturated growth rate at both seasonal and interannual time scales was highly significant (Table 1). Growth rates at ambient nutrients, $\mu_{a}(0.05)$, generally were similar to enriched growth rates until mid-year (Fig. 2a), indicating minimal nutrient limitation prior to that time. After that the degree of nutrient limitation at $D=0.05$ varied amongst years. Nutrient limitation of growth rate, indicated by $\mu_{a}(0.05)$ $\ll \mu_{\mathrm{e}}(0.05)$, was rare in 1992 (1 occurrence), 1995 (2 occurrences), and 1996 (1 occurrence), but common

Table 1. Analysis of variance in measured phytoplankton growth rates and microzooplankton grazing rates in the Rhode River, Maryland (USA), 1992 to $1996 . \mu_{e}(0.05)=$ phytoplankton growth rate with enriched nutrients; $\mu_{\mathrm{a}}(0.05)=$ growth rate with ambient nutrients; $g=$ microzooplankton grazing rates; $\mu_{\mathrm{n}}(0.05)-g=$ net growth rate. Table reports the fraction of variance $\left(r^{2}\right)$ associated with seasonal and interannual groupings, and $\mathrm{p}(F=0)$

\begin{tabular}{|lccccc|}
\hline Rate & \multicolumn{4}{c}{ Factor } & \\
& \multicolumn{2}{c}{ Season } & & Year \\
& $\mathrm{r}^{2}$ & $\mathrm{p}$ & & $\mathrm{r}^{2}$ & $\mathrm{p}$ \\
\hline$\mu_{\mathrm{e}}(0.05)$ & 0.16 & 0.007 & 0.16 & 0.003 \\
$\mu_{\mathrm{a}}(0.05)$ & 0.09 & 0.114 & 0.04 & 0.562 \\
$g$ & 0.17 & 0.003 & 0.08 & 0.139 \\
$\mu_{\mathrm{d}}(0.05)-g$ & 0.04 & 0.335 & 0.12 & 0.066 \\
\hline
\end{tabular}




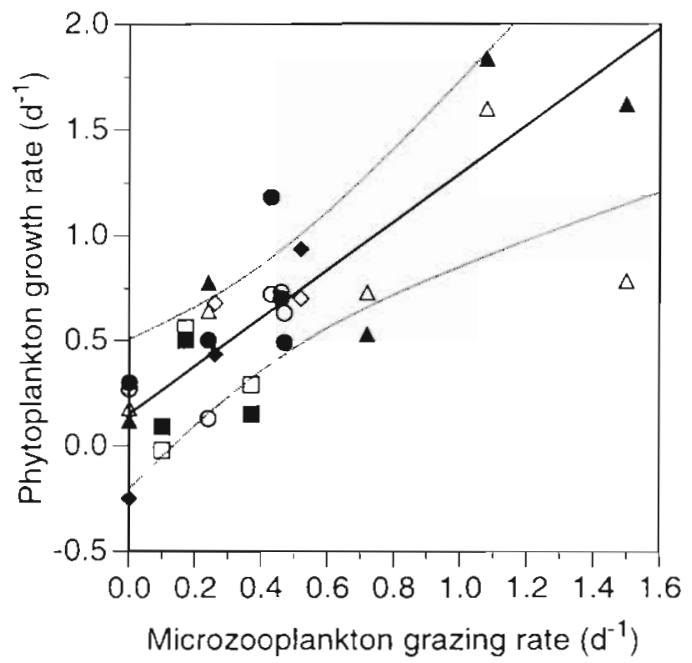

Fig. 3. Phytoplankton growth rate plotted against microzooplankton grazıng rate for different seasons in 1495 . Solıd sym. bols: added nutrients; open symbols: ambient nutrients: $(\square, \square)$ Winter/early spring; $(\bullet, 0)$ late spring; $(\Delta, \Delta) \operatorname{summer}(\bullet, \diamond)$ autumn/winter. Linear regression (solid line) and $99 \%$ confidence intervals (outer lines) are for nutrient-enhanced growin rates against microzoopiankion grazing rate

in the latter halves of 1993 and 1994 (Fig. 2a). Because of the more severe nutrient limitation in the summers of 1993 and 1994 , variance in $\mu_{a}(0.05)$ was not significant on either seasonal or interannual time scales (Table 1).

Grazing also was low in winter and spring, with peaks of about $1 \mathrm{~d}^{-1}$ in summer (Fig. 2b). Grazing rates were usually lower than nutrient-enhanced growth rates, $\mu_{e}(0.05)$, and often of similar magnitude to growth rates at ambient nutrients, $\mu_{a}(0.05)$. On 2 occasions grazing rate was much greater than $\mu_{a}(0.05)$. One occurred in August 1992 when growth rate was depressed on a rainy day and grazing rate was at a typical summer level. Another occurred in late June 1994 when $\mu_{\mathrm{a}}(0.05)$ was negative and much less than $\mu_{\mathrm{e}}(0.05)$, indicating severe nutrient limitation. Variance in grazing rate was highly significant among seasons, but not among years (Table 1).

Due to the similar seasonality of growth and grazing rates, phytoplankton net growth rate at ambient nutrients, $\mu_{a}(0.05)-g$, lacked definite seasonality (Fig. 2b), and variance among seasons and among years was not statistically significant (Table 1). Sporadic peaks in net growth rate occurred when grazing rates were low (May 1993, April and August 1994), and in one case when growth rate was high (July 1995). Episodes of elevated net growth rates were not associated with phytoplankton blooms (Gallegos unpubl.), indicating that such rates were not sustained long, or that rates measured in bottles were not representative of in situ rates.
For certain periods, fluctuations in microzooplankton grazing appeared to parallel changes in growth (Fig. 2b, especially 1995) but, pooling all data, correlation between grazing rate and growth rate was low, whether at enhanced nutrients $\left(\mathrm{r}^{2}=0.29\right)$ or at ambient nutrients $\left(r^{2}=0.13\right)$. The low correlation between growth and grazing was due to periods when growth greatly exceeded grazing (Fig. 2, especially summer 1994) or when growth rate was severely nutrient limited (Fig. 2a, especially summer 1993). Some patterns can be discemed, in spite of the low overall correlations, by examining relationships of phytoplankton growth to microzooplankton grazing in individual years. We begin with 1995 because that was the year with the widest range of observed growth and grazing rates (Fig. 2) and it had the highest correlation between the two (Fig. 3). Growth rates with added nutrients (Fig. 3, solid symbols) and at ambient nutrients (Fig. 3, open symbols) exhibited similar relationships with microzooplankton grazing rate in 1995 , with the exception of one instance of nutrient limitation in late summer (cf. Fig. 2a). A linear regression of nutrient-enhanced growth rate against microzooplankton grazing had an $r^{2}$ of 0.7 , and there was no obvious seasonal dependence of the relationship. For example, both the growth and the grazing rates measured in summer (Fig. 3, filled triangles) ranged from about 0 to $1.5 \mathrm{~d}^{-1}$, that is, the full range observed for the entire year. Other seasons, for example winter to early spring (Fig. 3, filled squares) had a smaller range (about 0 to $0.6 \mathrm{~d}^{-1}$ ) but generally fell within the $99 \%$ confidence intervals about the line. We use this line and confidence regions to evaluate the relationship between phytoplankton growth and microzooplankton grazing rates in other years, and to determine the causes of the overall low correlations in the entire data set.

In 1992 one point fell far outside the $99 \%$ confidence limits of the 1995 growth-grazing relationship, due to an unseasonably low measured growth rate that was not attributable to nutrient limitation (Fig. 4a). The outlier occurred in August when growth rates are frequently $>1 \mathrm{~d}^{-1}$ (Fig. 2) and may have been due to light limitation, as incident PFD on that day $\left(24.8 \mathrm{~mol} \mathrm{~m}^{-2}\right.$ $\mathrm{d}^{-1}$ ) was about half the highest values measured in August of other years. Other experiments that year resembled the growth-grazing relationship observed in 1995

In 1993 there was a cluster of growth rates at ambient nutrients (Fig. 4b, circles) that fell below the linear relationship based on 1995, whose corresponding measurements with enriched nutrients conformed to the 1995 relationship. Another point with $g=0 \mathrm{~d}^{-1}$ and growth rate $>1 \mathrm{~d}^{-1}$ measured in June of 1993 (cf. Fig. 2) was an outlier to the relationship for both enriched and 


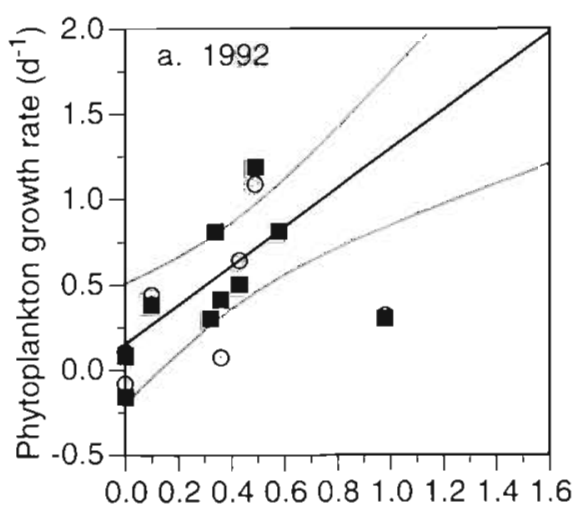

Microzooplankton grazing rate $\left(\mathrm{d}^{-1}\right)$

Microzooplankton grazing rate $\left(d^{-1}\right)$

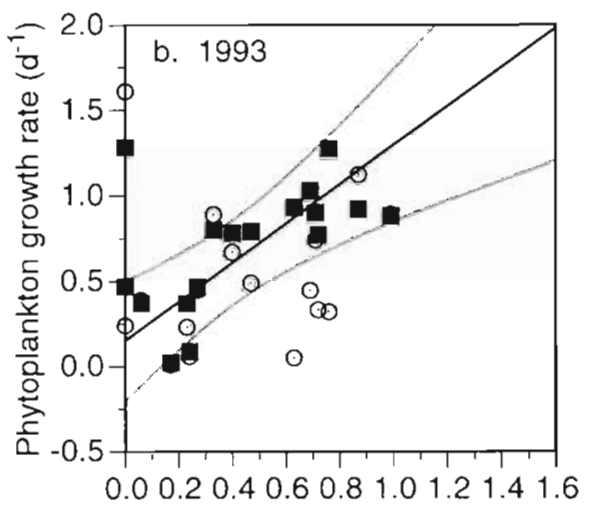

Microzooplankton grazing rate $\left(\mathrm{d}^{-1}\right)$

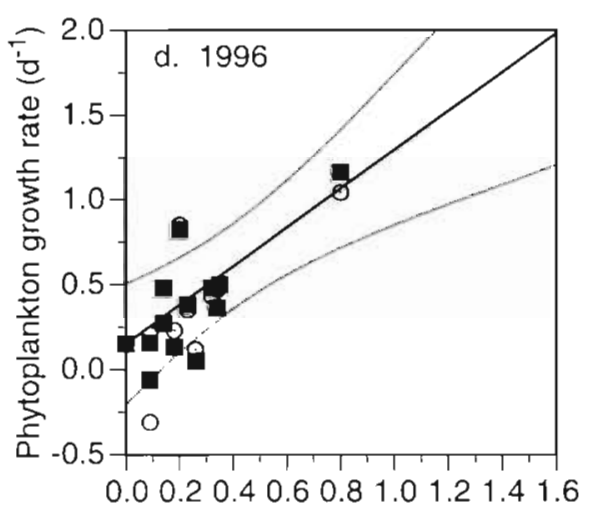

Microzooplankton grazing rate $\left(d^{-1}\right)$

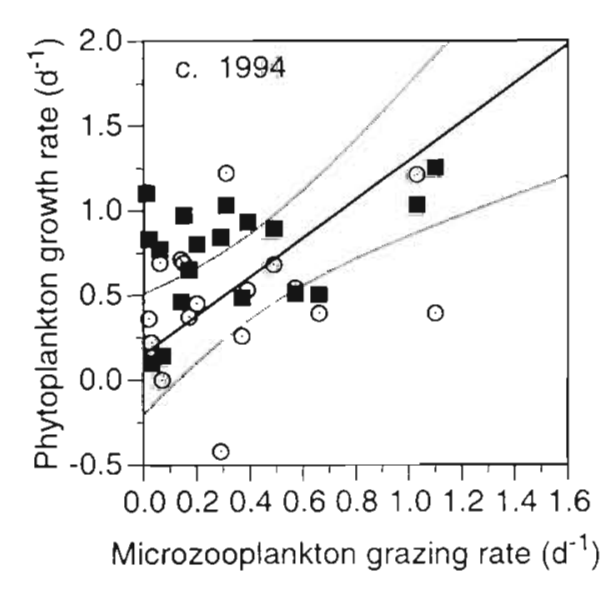

Fig. 4. Phytoplankton growth rate, with nutrients added (ם) or at ambient nutrients $(\odot)$, plotted against microzooplankton growth rate in the Rhode River: (a) 1992; (b) 1993; (c) 1994; (d) 1996. Regression (solid) lines and 99\% confidence intervals (outer lines) are those calculated for 1995 (see Fig. 3) ambient nutrients (Fig. 4b). This measurement was made as the system was recovering from extremely high flows of the Susquehanna River (Gallegos et al. 1997) and may have been conducted before the grazer community developed for that year. Other points for 1993 were very similar to the growth-grazing relationship observed in 1995.

There was no correlation between grazing and growth rates, with or without added nutrients, in 1994 (Fig. 4c). This year, together with the 2 largest outliers in 1992 and 1993, was principally responsible for the low overall correlation between phytoplankton growth rate and microzooplankton grazing rate. Growth and grazing rates in 1996 were mostly lower than in other years (Fig. 4d), but generally conformed to the relationship observed in Fig. 3. Overall, there appears to be an underlying relationship between phytoplankton growth rate and microzooplankton grazing rate (Fig. 3) from which the system only occasionally departs in most years (Fig. 4a, b), but sometimes departs for entire years (Fig. 4c). From the slope of a type 2 regression on the data in Fig. 3 (nutrient-enhanced growth rates), we estimate the ratio of grazing rate to growth rate to be 0.73 .

\section{Nutrients}

Assuming that addition of nutrients has no deleterious effect on phytoplankton growth, then we may consider cases in which $\mu_{a}>\mu_{e}$, i.e. cases of apparent 'negative enhancement', as a measure of the random error in the mean of duplicate measurements. We found that $95 \%$ of all such observations were of absolute value $<0.25 \mathrm{~d}^{-1}$, and we therefore consider stimulation of net growth rate by $0.25 \mathrm{~d}^{-1}$ as the lower limit for detecting significant enhancement by addition of nutrients. If this limit is an underestimate of the true error, then any conclusion about the lack of a significant stimulation by nutrient addition should be conservative.

Responses to nutrient additions changed seasonally. Prior to 10 April we observed no enhancement of net growth rates in $1 \mathrm{~d}$ incubations by addition of nutrients at any dilution factor (Fig. 5a). Net growth rates during this part of the year were low at all dilutions, ranging from 0 to $0.5 \mathrm{~d}^{-1}$. In late spring (11 April to 22 June), the range of observed growth rates expanded to about $1.5 \mathrm{~d}^{-1}$. At this time, there were a few instances of growth rate limitation by nutrients, where net growth rate at $D=0.05$ was enhanced by 

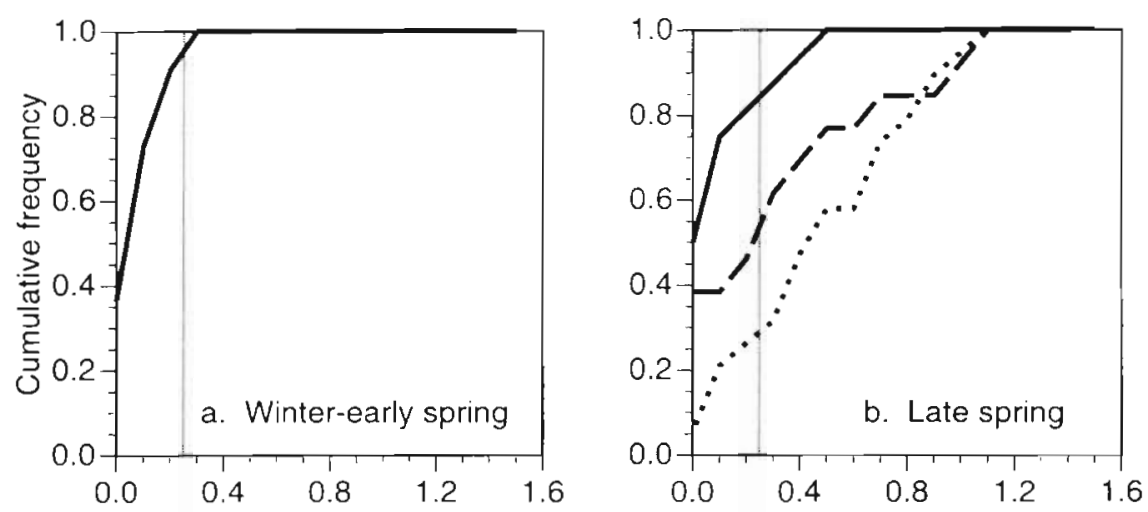

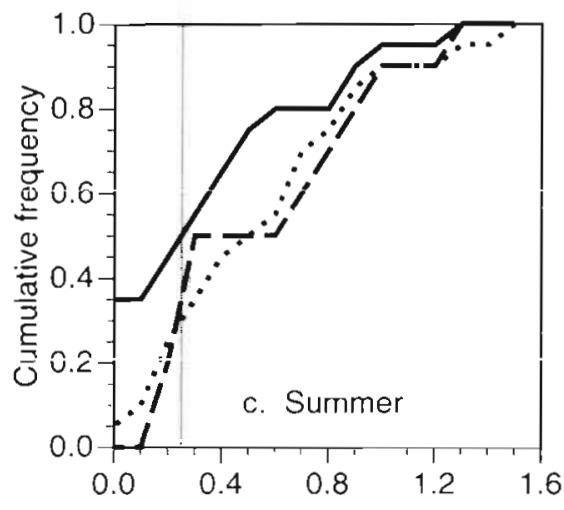

Growth rate increment, $\mu_{e}-\mu_{a}\left(d^{-1}\right)$

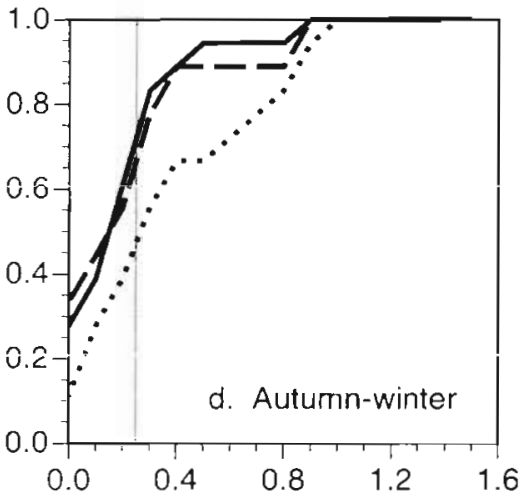

Growth rate increment, $\mu_{\mathrm{e}}-\mu_{\mathrm{a}}\left(\mathrm{d}^{-1}\right)$
Fig. 5. Cumulative distribution of the difference between nutrent enriched and ambient-nutrient growth rates in (a) winter to early spring, (b) late spring, (c) summer and (d) autumn/winter $D=1.0$ $(--)_{i} D=0.4(\cdots)$; and $D=0.05(-)$, except in (a), which shows all dilution levels combined. Vertical line at $0.25 \mathrm{~d}^{-1}$ is apparent limit of resolution nutrient addition (Fig. 5b, solid line); but $80 \%$ of growth rates at this dilution factor showed no detectable growth enhancement by nutrient addition. Potential nutrient limitation was common, as about two-thirds of the nutrient-enhanced growth rates at $D=0.4$ exceeded those without nutrient enrichment by $>0.25 \mathrm{~d}^{-1}$ (Fig. 5b, dotted line). About half the net growth rates in undiluted incubations were enhanced by nutrient addition, indicating that microzooplankton grazing was partially effective in relieving in situ nutrient limitation during late spring (Fig. 5b, dashed line).

In summer (22 June to 22 September) all but $30 \%$ of incubations at both $D=1.0$ and $D=0.4$ were enhanced by nutrient addition (Fig. $5 \mathrm{C}$ ). Nutrient limitation at $D=$ 0.05 was more common during summer than at any other time of the year, with $50 \%$ of growth rates enhanced by nutrient addition by $>0.25 \mathrm{~d}^{-1}$, some by as much as $1 \mathrm{~d}^{-1}$ (Fig. 5c, solid line).

In autumn and early winter (22 September to 31 December), about $70 \%$ of incubations at $D=0.05$ and at $D=1$ showed no effect from nutrient addition (Fig. $5 \mathrm{~d}$ ). Potential nutrient limitation was still prevalent, with about half the incubations stimulated by addition of nutrients, some by as much as $1 \mathrm{~d}^{-1}$ (Fig. 5d, dotted line). The range of observed absolute growth rates was reduced during this time, though not as much as during early spring.

\section{$\mathrm{N}$ versus $\mathrm{P}$ limitation}

There was considerable overlap in the times of year during which $N$ or P limitation was observed (Fig 6). $N$ limitation was observed as early as 12 April and as late as 14 November, and in every month in between (Fig. 6, circles). P limitation, when it occurred, was observed in winter, spring, and late autumn. The 2 instances of the greatest stimulation of net growth rate by addition of $P$ occurred late in the spring of 1993, when $\mathrm{NO}_{3}$ persisted later than usual due to unusually high spring flows of the Susquehanna River (Gallegos et al. 1997). This late-season persistence of $\mathrm{NO}_{3}$ resulted in stimulation by $\mathrm{P}$ of $>0.8 \mathrm{~d}^{-1}$; but otherwise, added $P$, when it made any difference at all, enhanced growth rate by $<0.3 \mathrm{~d}^{-1}$ (Fig. 6, triangles), near the detection limit. Instances of no stimulation by nutrient occurred in winter and spring, to as late as mid-June (Fig. 6, squares). Many more instances of enhancement by $\mathrm{N}$ alone were observed. From July through October we observed only $N$ limitation. Net growth rate during summer and autumn was frequently 
enhanced by $\mathrm{N}$ addition by $>0.6 \mathrm{~d}^{-1}$, with values ranging from negligible to $>1.2 \mathrm{~d}^{-1}$ (Fig, 6)

\section{Physical factors}

Nutrient-enhanced growth rates, $\mu_{e}(0.05)$, were not well-predicted by either temperature or in situ PFD (Fig. 7). The relationship between $\mu_{e}(0.05)$ and temperature exhibited considerable scatter, but was approximately bounded above by the curve of Eppley (1972) for a $14 \mathrm{~h}$ photoperiod, i.e. $\mu_{\mathrm{e}}(0.05)=1.44 \times$ $10^{\left.0.02751^{\circ} \mathrm{C}\right)-0.7}$ (Fig. $7 \mathrm{a}$ ). We divided the measured nutrient-enhanced growth rates by this factor (i.e. $1.44 \times$ $10^{00275 i^{\circ} \mathrm{C}-0.7}$ ) to normalize the growth rates for temperature effects, and then examined the relationship between normalized $\mu_{\mathrm{e}}(0.05)$ and in situ PFD (mol quanta $\mathrm{m}^{-2} \mathrm{~d}^{-1}$ ) at $1 \mathrm{~m}$ (Fig. 7b). Again, there was considerable scatter. Considering all data together, there was no significant relationship between temperaturenormalized growth rate and in situ PFD. However. there appeared to be a light-dependent separation in the data that (by inspection) divided the measurements into 2 groups, one having a light-saturated growth rate close to the temperature-dependent maximum (normalized growth rate $=1$; Fig. $7 b$, squares) and another with a maximum normalized growth rate of about 0.4 to 0.5 (Fig. $7 \mathrm{~b}$, circles). To determine if there was a floristic basis for the separation observed in Fig. $7 \mathrm{~b}$, we examined the phytoplankton species composition of the initial samples.

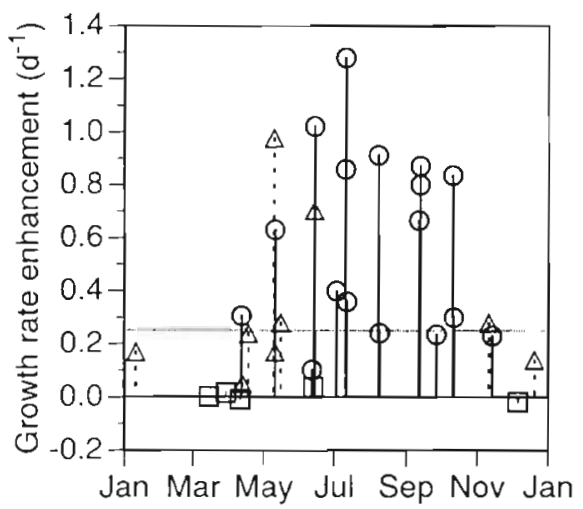

Fig. 6. Seasonal distribution of the magnitude of stimulation of net growth rate in incubations by addition of $\mathrm{N}$ alone $(0,-)$ by $\mathrm{P}$ alone $(\Delta,--)$, or no effect by addition of either nutrient (口). Growth rate increment $=\mu_{\mathrm{e}}-\mu_{\mathrm{a}}$. Horizontal dotted line is the $0.25 \mathrm{~d}^{-1}$ change detection limit. Coinciding dates are experiments done in different years. Points shown are the incubations at the dilution factor having the maximal increment in growth rate for each nutrient factorial experiment
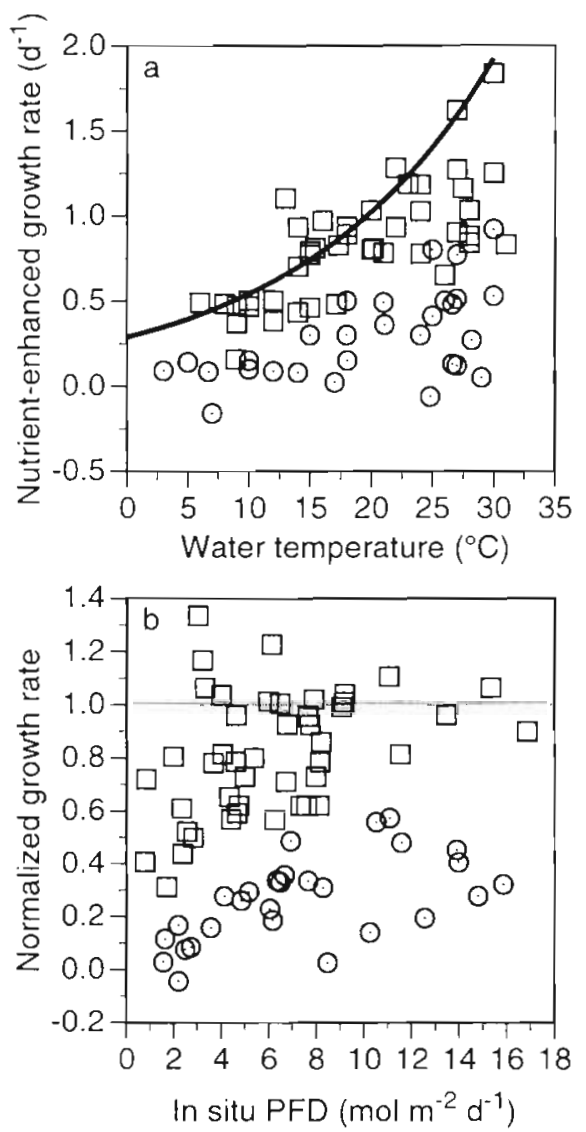

Fig. 7 (a) Nutrient-enhanced phytoplankton growth rate at dilution factor $D=0.05$ plotted against water temperature. Solid line is empirical curve of Eppley (1972) for phytoplankton cultures for a $14 \mathrm{~h}$ photoperiod. (b) Nutrient-enhanced net growth rate at dilution factor $D=0.05$ normalized to the temperature-dependent maximum [i.e. solid line in (a)] plotted against in situ photon flux density (PFD, 400 to $700 \mathrm{~nm}$ ). Horizontal line at 1.0 is temperature-dependent upper bound. Based on the vertical separation of the points in (b), the data were divided into high $(\square)$ and low $(\odot)$ response groups which were subjected to statistical analysis of phytoplankton species composition

\section{Phytoplankton species composition}

A total of 66 taxa were observed in the 76 experiments. The most frequently observed taxon, Cryptomonas sp., occurred 74 times; and 22 taxa occurred only once. Eighteen taxa occurred 16 or more times (i.e. in $20 \%$ of the samples) and there was a break in the frequency spectrum between 16 and 9 occurrences. Only those 18 taxa were considered for further statistical analysis.

We conducted a logistic regression analysis to predict the group designation of Fig. $7 \mathrm{~b}$ as the dependent variable, with the log-transformed abundances of the 18 taxonomic groupings as independent variables. Logistic regression is used to fit a categorical response vari- 
able (i.e. high vs low growth rate response group) as a linear function of 1 or more continuous variables (i.e. species abundances). Five taxa had highly significant coefficients (Table 2 ). Three diatoms, Thalassiosira pseudonana, Thalassiosira sp., and Nitzschia longisima, had positive coefficients and were associated with the fastergrowing group in Fig. 7b. Two dinoflagellates, Gyrodinium uncatenum and Prorocentrum minimum, had negative coefficients and were associated with the slower-growing group in Fig. $7 \mathrm{~b}$.

Because the groupings were subjectively assigned, we also conducted multiple linear regression of normalized growth rate on the abundances of the 18 phytoplankton taxa. A stepwise regression was used. All taxa were included in the initial analysis, and the taxon with the lowest $t$-statistic was omitted from successive iterations until the coefficients of all remaining taxa were significant with $p<0.1$. Again, 5 taxa had significant coefficients (Table 2), 4 of which were in common with those that were significant in the logistic regression. The diatoms Thalassiosira pseudonana and Thalassiosira sp. again had positive coefficients, and the dinoflagellates Gyrodinium uncatenum and Prorocentrum minimum had negative coefficients. In the multiple linear regression analysis, the chrysophyte Apedinella radians was negatively weighted along with the 2 dinoflagellates, and the diatom Nitzschia longissima did not enter the regression significantly. Overall, the 5 taxa, without any consideration of variation in PFD, explained about $31 \%$ of the variance in temperature-normalized growth rate.

\section{DISCUSSION}

\section{Growth and grazing rates}

It is frequently reported that phytoplankton growth and microzooplankton grazing rates are tightly coupled, as demonstrated by high correlation between the 2 rates (Burkhill et al. 1987; Riegman et al. 1993, their Table $1_{i}$ Verity 1986). In a much larger data set than previously examined, we found that there was an underlying linear relationship between phytoplankton growth rate and microzooplankton grazing rate that implied a $g: \mu$ ratio of 0.73 , which was generally robust, but had notable exceptions (Figs. 2 to 4 ). Phytoplankton growth and microzooplankton grazing were correlated throughout 1995 (Fig. 3) and for most of the experiments in other years except 1994, when an abrupt mid-summer decline in grazing rate eliminated the correlation for that year (Figs. $2 \& 4 \mathrm{c}$ ). The cause of such shifts in functioning is unclear, but we expect a detailed taxonomic analysis of the microzooplankton community will be necessary as a first step toward understanding the dynamics of the rate coefficients. Multiple linear regression of grazing rate on phytoplankton species abundances yielded no significant relationships (data not shown). Predation on microzooplankton, particularly rotifers, during summer outbreaks of the sea nettle Chrysaora quinquecirrha could cause such a shift (Dolan \& Gallegos 1992), but records of sea nettle abundance for this system are lacking Another interesting observation was that growth rates at ambient nutrients often fell below the linear relationship in 1993, while the nutrient-enhanced growth rates for these experiments fell close to the line (Fig. 4b). This may reflect a dependence on recycled nutrients at that time. Nutrients would become limiting at very low dilution factors because recycling due to grazing in those incubations would have been virtually eliminated (cf. Fig. 1c). Confirming this possibility would have required the full protocol of Andersen et al. (1991), which is able to identify the source of nutrients supplying phytoplankton growth.

Nutrient-enhanced growth rate differed significantly among seasons (Table 1). This was driven by the similar seasonality of temperature and PFD, although the responses of maximum growth rate to temperature and PFD differed among taxa (Fig. 7b). The occurrence of Prorocentrum minimum and Gyrodinium uncatenum, the main species associated with the slower growing assemblage, is highly seasonal, peaking in late spring and summer, but their dominance in the incubation experiments was too sporadic to affect the seasonality in $\mu_{e}(0.05)$. Unlike nutrient-enhanced growth, growth rate at ambient nutrients did not differ among seasons (Table 1) 
Microzooplankton grazing, by regenerating nutrients and removing phytoplankton biomass, evidently delays nutrient limitation in the late spring (Fig. 5b). During that season, net growth rate in half the undiluted incubations was unaffected by addition of nutrients, compared with only $25 \%$ unaffected by nutrient addition at $D=0.4$. Grazing had a similar effect in the autumn (Fig. 5d), but not in the summer (Fig. 5c), when $75 \%$ of the growth rates at both $D=1.0$ and $D=0.4$ were enhanced by addition of nutrients. Similar to observations by Strom \& Strom (1996), microzooplankton grazing rate was a higher fraction of unenriched phytoplankton growth rate than of nutrient-enhanced growth rate. Thus grazing more nearly balanced unenriched than nutrient-enriched growth rates.

This study has not considered grazing by copepods. The dominant copepods in the system are Eurytemora affinis, which has a peak in abundance in February and March, and Acartia tonsa, which is present year round and has sporadic peaks in the summer (Allan et al. 1976). With annual average densities of adult $A$. tonsa of about 0.5 ind. $1^{-1}$ (Allan et al. 1976), we would expect that copepods would be present only occasionally and unevenly in incubation bottles. Their most likely effect would be to cause poor replication between pairs of bottles, most frequently in the undiluted treatment, which is occasionally observed. Inclusion of copepods could cause either overestimates or underestimates of the microzooplankton grazing coefficient, depending on whether their diet was mainly phytoplankton or microzooplankton. Dolan \& Gallegos (1992) estimated that production by rotifers, included here in the operational definition of microzooplankton, exceeded that of copepods by an order of magnitude, as had been speculated by Allan et al. (1976). Thus, it would seem that microzooplankton account for most of the grazing mortality of phytoplankton reported in these coefficients, but further investigation of the magnitude of grazing by copepods in this system is warranted

\section{Nutrient limitation}

Bioassay experiments to test for nutrient limitation are usually incubated for several days to allow time for the system to respond to the addition of the limiting nutrient (Howarth 1988). Over several days, species composition of the plankton inside incubation bottles may change (Venrick et al. 1977). Thus the measured response after several days reveals the ecosystemlevel nutrient status (Howarth 1988), but, if the species composition changes substantially, long incubations will not provide accurate estimates of growth and grazing rate for the community existing at the start of the experiment. Our combination of nutrient additions with $1 \mathrm{~d}$ dilution experiments were intended to reveal growth and grazing rates of the plankton communities initially present, and may not, in every case, correctly identify the system-level status with respect to nutrient limitation. Our frequent observation of no response to added nutrients, particularly those in summer, may indicate times when the response to nutrient addition was delayed. Nevertheless, by making bi-weekly measurements over several years, we believe the overall seasonal pattern of nutrient limitation can be discerned.

Enhancement of net growth rate by addition of nutrients was first observed in late spring primarily in the $D=0.4$ dilution, which indicates a potential for nutrient limitation, provided microzooplankton grazing is reduced. This is a particularly revealing test, because it permits us to project the results beyond a $1 \mathrm{~d}$ incubation. For example, even when incubation at $D=1.0$ indicates that nutrient addition has no effect on net growth rate, the possibility remains that a species that is slower growing, has high nutrient demand, and is not well grazed by the microzooplankton community present might begin to bloom if the nutrients were added to the natural system. Similarly, the model of Gallegos et al. (1992) simulates bloom formation as the result of a shift to poorly grazed taxa within the context of a nutrient-saturated growth model (Wofsy 1983). Our experiments do not confirm that blooms are accompanied by a reduction of grazing loss rate, but they do indicate that, in late spring, nutrient addition will usually not stimulate biomass accumulation unless grazing is partially reduced.

By mid- to late summer nutrient limitation was common at all dilution levels, even at $D=0.05$, where added nutrients enhanced net growth in half the experiments. During summer, the input of nutrients from the local watershed (Correll \& Ford 1982) and from the mainstem Chesapeake Bay are negligible (Fisher et al. 1992), so that water column regeneration (i.e. grazing) and benthic fluxes are the only sources to sustain phytoplankton growth. Ordinarily these processes sustain summertime ambient concentrations of about $1 \mu \mathrm{M}$ DIP and 1 to $3 \mu \mathrm{M}$ dissolved $\mathrm{NH}_{4}$ in segment 4 of the Rhode River (Jordan et al. 1991a). These ambient concentrations, particularly of $\mathrm{N}$, are frequently insufficient in the summer to support maximal growth rate for 1 d even of 5 percent of the initial phytoplankton biomass. The dilution, however, cuts off the regenerative source (Andersen et al. 1991), and bottle enclosure cuts off benthic fluxes in this shallow system. Perhaps in situ incubation at $D=0.05$ using a diffusion chamber (which uses membrane filters to contain the plankton but allows nutrients to diffuse to the phytoplankton; e.g. Furnas 1982) might support 
maximal growth rate during summer, but biomass yield is obviously strongly nutrient limited.

\section{$\mathbf{N}$ versus $\mathbf{P}$ limitation}

Enhancement of net growth rate by addition of $\mathrm{N}$ alone was much more common than that by addition of $\mathrm{P}$ alone (Fig. 6). In general, addition of $\mathrm{N}$ to $\mathrm{N}$-limited populations resulted in greater enhancement of net growth rate than did addition of $\mathrm{P}$ to P-limited phytoplankton. Two exceptions occurred in the late spring of 1993, when extremely high flows from the Susquehanna River maintained lower salinities and higher levels of $\mathrm{NO}_{3}$ in the Rhode River than in most years. The persistent $\mathrm{NO}_{3}$ in that year meant that $\mathrm{P}$ limitation occurred when temperature and incident irradiance were higher, compared with other times when $\mathrm{P}$ was limiting. Thus the $P$ addition had a greater effect in those 2 instances than usually was the case. Except for that year, P limitation was never observed from midJune through mid-October (Fig. 6). Other instances of apparent $\mathrm{P}$ limitation occurred in winter and early spring. At that time, physical factors (presumably) constrained maximal growth rates to $<0.6 \mathrm{~d}^{-1}$, and the resultant enhancement of net growth rates, though often consistently higher with added $P$, was generally less than the $0.25 \mathrm{~d}^{-1}$ level of significance. Thus, lack of precision of incubation experiments may have prevented us from observing $P$ limitation in spring, when high N:P ratios (Jordan et al. 1991a) suggest potential $P$ limitation. In the companion paper (Gallegos \& Jordan 1997) we use a model of nutrient-limited phytoplankton growth, which is not subject to random experimental imprecision, to investigate the expected magnitude of response to $\mathrm{P}$ inputs in the spring. This model indicates that responses to $P$ additions that are too small to detect in our experiments can have large effects on phytoplankton growth at time scales $>1 \mathrm{~d}$.

A similar pattern of weak $P$ limitation in winter and spring followed by strong $N$ limitation during summer was observed by D'Elia et al. (1986) in the Patuxent River. In the mainstem of Chesapeake Bay, Fisher et al. (1992) also found a shift from P limitation immediately following the spring runoff maximum to $\mathrm{N}$ limitation during the period of seasonally low runoff. Four separate indicators (concentration ratios, alkaline phosphatase activity, nutrient turnover times, and enrichment bioassays) operating on different time and space scales gave congruent indications of which nutrient was limiting during each period. In the Delaware Estuary, Pennock \& Sharp (1994) observed light limitation during winter, $P$ limitation in late spring, and the potential for $N$ limitation in summer alleviated by grazing
Observed patterns in these systems have been related to seasonality in the processes that supply the dif ferent nutrients. Generally, P limitation in spring in the Chesapeake region results from excess dissolved inorganic nitrogen (DIN) concentrations in. Susquehanna River flow, which peaks at this time (Fisher et al. 1992). Pennock \& Sharp (1994) attributed P limitation in the Delaware Estuary to $\mathrm{P}$ depletion by phytoplankton during the spring period of active growth and biomass accumulation, with concentrations rising again later in summer as a result of regeneration. The apparent absence of severe $\mathrm{N}$ limitation during summer in the Delaware Estuary was attributed to continued riverine influx from upstream municipal sources (Pennock \& Sharp 1994). In the Rhode River subestuary, both $N$ and $P$ enter from the local watershed, but only $N$ enters appreciably at the subestuary mouth due to flow of the Susquehanna River (Jordan et al. 1991a). Seasonally this source is likely the dominant DIN source for the lower Rhode River estuary (Jordan et al. 1991a). Dissolved inorganic $\mathrm{N}$ and $\mathrm{P}$ entered the subestuary from the local watershed in the molar ratio of 26 , but left at a ratio of 2.7 due to uptake of DIN by phytoplankton and to release of deposited particulate $P$ from the sediments (Jordan et al. 1991a). The dependence of patterns of $\mathrm{N}$ and $\mathrm{P}$ limitation on supply rates by hydrologic loading and benthic remineralization is investigated using a model in which these factors are easily manipulated (Gallegos \& Jordan 1997).

\section{Physical factors}

The absence of enhancement of net growth rate by addition of nutrients at any dilution factor prior to 10 April (Fig. 5a) implies that physical factors constrained phytoplankton growth rates during that period. Growth rates were low during this period $\left(<0.6 \mathrm{~d}^{-1}\right)$, as were grazing rates (Fig. 2). Physical factors appear to become important again in late autumn. Some nutrient limitation persisted into the autumn (Fig. $5 \mathrm{~d}$ ), but most growth rates at $D=0.05$ were unaffected by nutrient addition in autumn and early winter

The relationship between nutrient-enhanced phytoplankton growth rate and temperature in the Rhode River (Fig. 7a) was similar to that observed in unialgal phytoplankton cultures grown at nutrient-saturation and constant light (Eppley 1972). Eppley's equation, which implies a $Q_{10}$ of 1.88 , was an upper bound for $>85 \%$ of the observations, and all but 1 fell within $0.25 \mathrm{~d}^{-1}$ of the curve. As with culture data, many points fell far below the upper bound (Fig. 7a). Eppley (1972) attributed the observed scatter to species-dependent differences in maximal growth rate and in temperature optima. In an environment as dynamic as estuaries, 
frequent mismatch between environmental conditions and optima of the species present can be expected.

In these data there is the additional variable of in situ PFD (Fig. 7b). After dividing by the temperaturedependent maximum, there remained much scatter in the relationship between PFD and nutrient-saturated growth rate (Fig. $7 \mathrm{~b}$ ). There is, of course, no reason to expect a single curve to fit all points due to interspecific difference in growth-irradiance responses (Langdon 1988) and due to adaptations to temporally fluctuating irradiance (Cullen 1990). Indeed, abundances of 5 taxa were significant explanatory variables in the logistic regression of subjectively assigned groupings in Fig. $7 \mathrm{~b}$; and these taxonomic groupings corresponded with the well-known differences in maximal growth rates between diatoms and dinoflagellates (Banse 1982).

The accasional occurrence of near 0 growth rates (Fig. 2a) with nutrients added, grazing virtually eliminated $(D=0.05)$, temperatures $>20^{\circ} \mathrm{C}$, and in situ $\mathrm{PFD}$ $>8 \mathrm{~mol}$ quanta $\mathrm{m}^{-2} \mathrm{~d}^{-1}$ (Fig. 7) is puzzling. These observations suggest that at times the phytoplankton community may be senescent, and that an adaptation period $>1$ d may be necessary to utilize the added nutrients.

\section{Summary}

The controls on phytoplankton growth show clear seasonal shifts in the Rhode River. The pattern that emerges for this eutrophic system is that physical factors are the main controls in late winter and early spring (Fig. 5a). Temperature is an upper bound of nutrient-enhanced growth rate in an expected manner during all seasons (Fig. 7a), but the relationship of nutrient-enhanced growth rate with in situ PFD is noisy (Fig. 7 b) and has a significant taxonomic dependence (Table 2). Nutrient limitation is first observed in late spring in incubations in which microzooplankton grazing is partially reduced by dilution (Fig. 5b). At this time the distinctions amongst potential nutrient limitation $(D=0.4)$, yield limitation $(D=1.0)$ and rate limitation $(D=0.05)$ are best observed. In summer, nutrients (specifically $N$ ) limit biomass accumulation at all dilution levels on most (but not all) dates (Fig. 5c); and, in autumn, nutrient limitation becomes less frequent and indicates that the system is returning to the winter-early spring condition.

\section{Management implications}

The frequent observation of nutrient limitation in summer cannot be interpreted to mean that nutrient inputs have been reduced sufficiently to reverse eutrophication of the system. Nutrient limitation occurs in the summer because a well-developed autotrophic community has sequestered available limiting nutrient, exclusive of that being recycled. A more reliable indicator of restored health would be an increased frequency of nutrient limitation of growth rate (i.e. at $D=$ 0.05 ) in late spring when autotrophic biomass normally accumulates in the system-that is, if Fig. 5b more nearly resembled Fig. $5 c$.

Precautions against using single indices of nutrient limitation, such as bioassay experiments, have been noted previously (e.g. Fisher et al. 1992). This work has shown that isolated bioassay experiments may indicate no effect of added nutrients (i.e. $\mu_{e}-\mu_{a}<0.25 \mathrm{~d}^{-1}$ ) in any season (Fig. 5), or sometimes for complete years in highly diluted samples (Fig. 2a, 1996). The taxonomic dependence of maximal growth rate may also obscure the observed response to added nutrients. Seasonal patterns only emerge when data are seasonally pooled over many experiments in different years.

Acknowledgements. This research was supported by the Smithsonian Environmental Sciences Program. We thank P. Neale and 3 anonymous reviewers for comments on an earlier version of the paper and $\mathrm{S}$. Hedrick for assistance with the experiments.

\section{LITERATURE CITED}

Allan JD, Kinsey TG, James MC (1976) Abundances and production of copepods in the Rhode River subestuary of Chesapeake Bay. Chesapeake Sci 17:86-92

Andersen T, Schartala AKL, Paasche E (1991) Quantifying external and internal nitrogen and phosphorus pools, as well as nitrogen and phosphorus supplied through remineralization, in coastal marine plankton by means of a dilution technique. Mar Ecol Prog Ser 69:67-80

Banse $K$ (1982) Cell volumes, maximal growth rates of unicellular algae and ciliates, and the role of ciliates in the marine pelagıal. Limnol Oceanogr 27:1050-1058

Burkhill PH, Mantoura RFC, LLewllyn CA, Owens NJP (1987) Microzooplankton grazing and selectivity of phytoplankton in coastal waters. Mar Biol 93:581-590

Cloern JE (1987) Turbidity as a control on phytoplankton biomass and productivity in estuaries. Cont Shelf Res 7 $1367-1381$

Correll DL, Ford D (1982) Comparison of precipitation and land runoff as sources of estuarine nitrogen. Estuar Coast Shelf Sci 15:45-56

Cullen JJ (1990) On models of growth and photosynthesis in phytoplankton. Deep Sea Res 37:667-683

D'Elia CF, Sanders JG, Boynton WR (1986) Nutrient enrichment studies in a coastal plain estuary: phytoplankton growth in large-scale, continuous cultures. Can J Fish Aquat Sci 43:397-406

Dolan JR, Gallegos C (1992) Trophic role of planktonic rotifers in the Rhode River Estuary, spring-summer 1991 Mar Ecol Prog Ser 85:187-199

Elser JJ, Frees DL (1995) Microconsumer grazing and sources of limiting nutrients for phytoplankton growth: application 
and complications of a nutrient-deletion/dilution-gradient technique. Limnol Oceanogr 40:1-16

Eppley RW (1972) Temperature and phytoplankton growth in the sea. Fish Bull 70:1063-1085

Fisher TR, Peele ER, Ammerman JW, Harding LWJ (1992) Nutrient limitation of phytoplankton in Chesapeake Bay. Mar Ecol Prog Ser 82:51-63

Furnas MJ (1982) An evaluation of two diffusion culture techniques for estimating phytoplankton growth rates in situ. Mar Biol 70:63-72

Gallegos CL (1989) Microzooplankton grazing on phytoplankton in the Rhode River, Maryland: nonlinear feeding kinetics. Mar Ecol Prog Ser 57:23-33

Gallegos CL, Jordan TE (1997) Seasonal progression factors limiting phytoplankton pigment biomass in the Rhode River estuary, Maryland (USA). II. Modeling N versus P Limitation. Mar Ecol Prog Ser 161:199-212

Gallegos CL, Jordan TE, Correll DL (1992) Event-scale response of phytoplankton to watershed inputs in a subestuary: timing, magnitude, and location of phytoplankton blooms. Limnol Oceanogr 37:813-828

Gallegos CL. Jordan TE. Correll DL (1997) Interanmual variability in spring bloom timing and magnitude in the Rhode River, Maryland (USA): observations and modeling. Mar Ecol Prog Ser 154:27-40

Gallegos CL, Vant WN, Safi K (1996) Microzooplankton grazing of phytoplankton in Manukau Harbour, North Island. NZ J Mar Freshwat Res 30:423-434

Harrison WG (1992) Regeneration of nutrients. In: Falkowski PG, Woodhead AD (eds) Primary productivity and biogeochemical cycles in the sea. Plenum Press, New York, p 385-4.07

Holm-Hansen O, Lorenzen CJ, Holmes RW, Strickland JDH (1965) Fluorometric determination of chlorophyll. J Cons Perm Int Explor Mer 30:3-15

Howarth RW (1988) Nutrient limitation of net primary production in marine ecosystems. Annu Rev Ecol Syst 19: $89-110$

Jordan TE, Correll DL, Miklas J, Weller DE (1991a) Nutrients and chlorophyll at the interface of a watershed and an estuary. Limnol Oceanogr 36:251-267

Jordan TE, Correll DL, Miklas J, Weller DE (1.991b) Longterm trends in estuarine nutrients and chlorophyll, and short-term effects of variation in watershed discharge.

Editorial responsibility: Otto Kinne (Editor).

Oldendorf/Luhe, Germany
Mar Ecol Prog Ser. 75:121=132

Landry MR, Hassett RP (1982) Estimating the grazing impact of marne micro-zooplankton. Mar Biol 67:283-288

Langdon C (1988) On the causes of interspecific differences in the growth-irradiance relationship for phytoplankton. II. A general review. J Plankton Res 10:1291-1312

Mallin MA, Paerl HW, Rudek J, Bates PW (1993) Regulation of estuarine primary production by rainfall and river flow. Mar Ecol Prog Ser 93:199-203

Malone TC, Conley DJ, Fisher TR, Glibert PM, Harding LW, Sellner KG (1996) Scales of nutrient-limited phytoplankton productivity in Chesapeake Bay. Estuaries 19:371-385

Malone TC, Crocker LH, Pike SE, Wendler BW (1988) influences of river flow on the dynamics of phytoplankton production in a partially stratified estuary. Mar Ecol Prog Ser 48:235-249

Paasche E, Erga SR (1988) Phosphorus and nitrogen limitation of phytoplankton in the inner Oslofjord (Norway). Sarsia 73:229-243

Pennock JR, Sharp JH (1994) Temporal alternation between light- and nutrient-limitation of phytoplankton production in a coastal plain estuary. Mar Ecol Prog Ser 111:275-288

Riegman R, Kuipers BR, Noordeloos AAM, Witte HJ (1993) Size-differential control of phytoplankton and the structure of plankton communities. Neth J Sea Res 31:255-265

Riegman R, Mur LR (1984) Theoretical considerations on growth kinetics and physiological adaptation of nutrientlimited phytoplankton. Arch Microbiol 140:96-100

Rudek J, Paerl HW, Mallin MA, Bates PW (1991) Seasonal and hydrological control of phytoplankton nutrient limitation in the lower Neuse River Estuary, North Carolina. Mar Ecol Prog Ser 75:133-142

Strom SL, Strom MW (1996) Microplankton growth, grazing, and community structure in the northern Gulf of Mexico Mar Ecol Prog Ser 130:229-240

Venrick EL, Beers JR, Heinbokel JF (1977) Possible consequences of containing microplankton for physiological rate measurements. J Exp Mar Biol Ecol 26:55-76

Verity PG (1986) Grazing of phototrophic nanoplankton by microzooplankton in Narragansett Bay. Mar Ecol Prog Ser 29:105-115

Wotsy SC (1983) A simple model to predict extinction coefficients and phytoplankton biomass in eutrophic waters. Limnol Oceanogr 28:1144-1155

Submitted: November 26, 1996; Accepted: November 17, 1997 Proofs received from author(s): December 23, 1997 